\title{
MicroRNA-30a-5p inhibits the proliferation and invasion of gastric cancer cells by targeting insulin-like growth factor 1 receptor
}

\author{
YANG LIU ${ }^{1}$, YU ZHOU ${ }^{2}, \mathrm{XUN} \mathrm{GONG}^{3}$ and CHANGJIE ZHANG ${ }^{1}$ \\ Departments of ${ }^{1}$ Rehabilitation, ${ }^{2}$ Neurosurgery and ${ }^{3}$ Emergency, \\ Second Xiangya Hospital of Central South University, Changsha, Hunan 410011, P.R. China
}

Received September 20, 2015; Accepted March 31, 2017

DOI: $10.3892 / \mathrm{etm} .2017 .4477$

\begin{abstract}
MicroRNAs (miRs) are a class of small non-coding RNAs of 18-25 nucleotides in length that serve as key regulators in the development and progression of human cancers. Recently, miR-30b-5p, as a member of the miR-30 family, has been reported to act as a tumor suppressor in gastric cancer. However, the expression and function of miR-30a-5p in gastric cancer, as well as the corresponding underlying mechanism, remain unknown. In the present study, it was demonstrated that the expression of miR-30a-5p was significantly reduced in gastric cancer tissues $(n=43)$ compared with normal gastric tissues $(n=10 ; P<0.01)$. Similarly, miR-30a-5p was significantly downregulated in the gastric cancer cell lines AGS, HGC27, BGC823 and SGC7901, when compared with the normal gastric mucosa epithelial cell line GES-1 ( $\mathrm{P}<0.01)$. In addition, overexpression of miR-30a-5p significantly inhibited the proliferation and invasion of AGS cells $(\mathrm{P}<0.01)$. Insulin-like growth factor 1 receptor (IGF-1R) was identified as a novel target of miR-30a-5p, and the protein expression of IGF-1R was negatively regulated by miR-30a-5p in AGS cells $(\mathrm{P}<0.01)$. Furthermore, overexpression of IGF-1R significantly reversed the inhibitory effect of $\mathrm{miR}-30 \mathrm{a}-5 \mathrm{p}$ on the proliferation and invasion of AGS cells $(\mathrm{P}<0,01)$, indicating that IGF-1R was involved in miR-30a-5p-mediated proliferation and invasion of AGS cells. It was also observed that the expression of IGF-1R mRNA was upregulated in gastric cancer tissues compared with normal gastric tissues $(\mathrm{P}<0.01)$, and its levels of expression were reversely correlated with that of miR-30a-5p in gastric cancer tissues $\left(\mathrm{R}^{2}=0.3892 ; \mathrm{P}<0.01\right)$. Collectively, these data suggest that miR-30a-5p inhibits the growth and metastasis
\end{abstract}

Correspondence to: Professor Changjie Zhang, Department of Rehabilitation, Second Xiangya Hospital of Central South University, 139 Middle Renmin Road, Changsha, Hunan 410011, P.R. China

E-mail: csuzhangchangjie@sina.com

Key words: gastric cancer, microRNA-30a-5p, insulin-like growth factor 1 receptor, proliferation, invasion of gastric cancer by directly targeting IGF-1R. Therefore, the miR-30a-5p/IGF-1R axis may be a potential therapeutic target in the treatment of gastric cancer.

\section{Introduction}

Gastric cancer is among the most common types of human cancer and has a poor 5-year survival rate, primarily due to its high rates of recurrence and metastasis $(1,2)$. Although advances in the diagnosis and treatment of gastric cancer have been made, gastric cancer remains to be among the top five cancers worldwide in terms of cancer-related mortality (1-3). Thus, elucidation of the molecular mechanisms underlying the development and progression of gastric cancer is required to develop effective strategies for its treatment $(4,5)$.

MicroRNAs (miRs), as a class of small non-coding RNAs of 18-25 nucleotides in length, serve as regulators of gene expression by binding directly to the 3'-untranslational region (UTR) of their target mRNAs, which leads to mRNA degradation and/or translation inhibition $(6,7)$. MiRs have been found to participate in the regulation of various biological processes, including cell proliferation, differentiation, apoptosis and motility and cell cycle progression $(7,8)$. Moreover, many oncogenes and tumor suppressor genes are the targets of miRs, and thus miRs serve key roles in various human cancers, including gastric cancer (9-12). For instance, a previous study observed that miR-126 was significantly downregulated in gastric cancer, and its downregulation was associated with malignant progression (13). MiR-30a-5p, as a member of the miR-30 family, was recently observed to be significantly downregulated in gastric cancer due to high promoter methylation induced by DNA methyltransferase 1 (14). Moreover, reduced expression of miR-30a-5p has been associated with a high rate of lymph node metastasis (14). These data suggest that miR-30a-5p may serve a suppressive role in gastric cancer. However, data on the regulatory role of miR-30a-5p in the growth and metastasis of gastric cancer are limited.

Insulin-like growth factor 1 receptor (IGF-1R) is a key member of the IGF receptor family, and exhibits a high affinity for insulin-like growth factor (15). Previous studies have indicated that IGF-1R may be involved in malignant transformation events $(16,17)$. IGF-1R is expressed to a high level in various 
human cancer tissues, where it promotes the survival and inhibits the apoptosis of cancer cells, indicating that IGF-1R may be a key oncogene and therapeutic target in the treatment of human cancers, including gastric cancer (15-19). Recently, Ge et al (20) reported that inhibition of IGF-1R with small interfering (si)-RNA inhibited the proliferation, cell cycle progression, migration and invasion of gastric cancer cells, and led to their apoptosis. However, the regulatory mechanism of IGF-1R expression remains unknown, and thus insight into the regulation of IGF-1R may aid to develop more effective strategies for the treatment of gastric cancer.

Therefore, the present study aimed to elucidate the molecular mechanism of miR-30a-5p in regulating the proliferation and invasion of gastric cancer cells.

\section{Materials and methods}

Tissue specimen collection. The present study was approved by the Ethics Committee of the Second Xiangya Hospital of Central South University (Changsha, China). A total of 43 gastric cancer tissues and 10 matched adjacent normal gastric tissues were obtained from patients at the Second Xiangya Hospital of Central South University from January 2013 to December 2013. Written informed consent was obtained from all patients in the current study. The patients included 18 females and 25 males with a mean age of $54.2 \pm 7.8$ years. Cancers were classified as T1 or T2-T4 stage (21). The clinical information of gastric cancer patients is summarized in Table I. All tissues were immediately snap-frozen in liquid nitrogen following surgical removal and stored at $-80^{\circ} \mathrm{C}$ until use.

Cell culture. Four common human gastric cancer cell lines, AGS, HGC27, BGC823 and SGC7901, and the normal gastric mucosa epithelial cell line GES-1 were purchased from the Cell Bank of Type Culture Collection of the Chinese Academy of Sciences (Shanghai, China). Cells were cultured in Dulbecco's modified Eagle's medium (DMEM; Thermo Fisher Scientific, Inc., Waltham, MA, USA) with $10 \%$ fetal bovine serum (FBS; Thermo Fisher Scientific, Inc.) at $37^{\circ} \mathrm{C}$ in a humidified incubator containing $5 \% \mathrm{CO}_{2}$.

Reverse transcription-quantitative polymerase chain reaction $(R T-q P C R)$. Total RNA was extracted from gastric tissue and cells with TRIzol ${ }^{\circledR}$ reagent (Thermo Fisher Scientific, Inc.), according to the manufacturer's protocol. Total RNA was then converted into cDNA using a High Capacity cDNA Reverse Transcription kit (Thermo Fisher Scientific, Inc.) according to the manufacturer's instructions. Reverse transcription was performed at $16^{\circ} \mathrm{C}$ for $30 \mathrm{~min}$, followed by an incubation at $42^{\circ} \mathrm{C}$ for $30 \mathrm{~min}$ and enzyme inactivation at $85^{\circ} \mathrm{C}$ for $5 \mathrm{~min}$. PCR was subsequently performed to measure the expression of miR-30a-5p using an miRNA Q-PCR Detection kit and SYBR-Green (both from GeneCopoeia, Inc., Rockville, MD, USA) on an ABI 7500 thermocycler (Thermo Fisher Scientific, Inc.) under the following conditions: $95^{\circ} \mathrm{C}$ for $10 \mathrm{~min}$, followed by 45 cycles of $95^{\circ} \mathrm{C}$ for $15 \mathrm{sec}$ and $60^{\circ} \mathrm{C}$ for $15 \mathrm{sec}$. The U6 gene (primer sequences not provided by manufacturer) was used as an internal reference. The expression of IGF-1R mRNA was detected by qPCR using a standard SYBR-Green RT-PCR kit (Takara Bio, Inc., Otsu, Japan), in accordance with the manufacturer's instructions. GAPDH was used as an internal reference. The specific primers used to detect IGF-1R were as follows: Forward, 5'-ATGCTGACCTCTGTTACCTCT-3' and reverse, 5'-GGCTTATTCCCCACAATGTAGTT-3'. The specific primers used for GAPDH were as follows: Forward, 5'-CTGGGCTACACTGAGCACC-3' and reverse, 5'-AAGTG GTCGTTGAGGGCAATG-3'. The reaction was performed at $95^{\circ} \mathrm{C}$ for $5 \mathrm{~min}$, followed by 40 cycles of denaturation at $95^{\circ} \mathrm{C}$ for $15 \mathrm{sec}$ and an annealing/elongation step at $60^{\circ} \mathrm{C}$ for $30 \mathrm{sec}$. The mRNA expression levels of miR-30a-5p and IGF-1R were normalized to that of U6 and GAPDH, respectively. Relative expression was analyzed by the $2^{-\Delta \Delta \mathrm{Cq}}$ method (22). PCR was performed in triplicate.

Western blot analysis. Cells were solubilized in cold radioimmunoprecipitation assay lysis buffer (Thermo Fisher Scientific, Inc.). The concentration of protein was determined using a bicinchoninic acid (BCA) Protein Assay kit (Pierce; Thermo Fisher Scientific, Inc.), according to the manufacturer's instructions. The protein was extracted by centrifugation at $12,000 \times \mathrm{g}$ for $20 \mathrm{~min}$ at $4^{\circ} \mathrm{C}$. Proteins $(50 \mu \mathrm{g})$ were loaded and separated using $10 \%$ SDS-PAGE and transferred onto a poly vinylidene difluoride membrane (Thermo Fisher Scientific, Inc.). The membrane was incubated with phosphate-buffered saline (PBS) containing 5\% skimmed milk (China Mengniu Dairy Co., Ltd., Hong Kong, China) overnight at $4^{\circ} \mathrm{C}$, followed by incubation with rabbit anti-IGF-1R monoclonal antibody (1:500; sc-7952) or rabbit anti-GAPDH monoclonal antibody (1:500; sc-367714; both from Santa Cruz Biotechnology, Inc., Dallas, TX, USA) at room temperature for $3 \mathrm{~h}$. Following three washes with PBS, the membrane was incubated with mouse anti-rabbit IgG conjugated to alkaline phosphatase (1:5,000; sc-2358; Santa Cruz Biotechnology, Inc.) at room temperature for $1 \mathrm{~h}$. An enhanced chemiluminescence kit (Pierce; Thermo Fisher Scientific, Inc.) was then used to perform chemiluminescent detection, according to the manufacturer's instructions. Protein expression was analyzed using Image-Pro Plus software 6.0 (Media Cybernetics, Inc., Rockville, MD, USA). Relative protein expression was represented as a density ratio compared to that of GAPDH. The experiments were performed in triplicate.

Transfection. Lipofectamine ${ }^{\circledR} 2000$ (Thermo Fisher Scientific, Inc.) was used to perform cell transfection according to the manufacturer's instructions. For miR-30a-5p and IGF-1R function analysis, AGS cells ( $1 \times 10^{5}$ cells) were cultured to $70 \%$ confluence in DMEM supplemented with $10 \% \mathrm{FBS}$ at $37^{\circ} \mathrm{C}$ in a humidified incubator containing $5 \% \mathrm{CO}_{2}$. Subsequently, cells were transfected with $100 \mathrm{~nm}$ negative control miR (miR-NC group), miR-30a-5p mimic (miR-30a-5p group; all from GeneCopoeia, Inc.) or miR-30a-5p mimic and IGF-1R plasmid (miR-30a-5p+IGF-1R group; Amspring, Changsha, China), respectively. AGS cells alone were considered as the non-transfected control group.

MTT assay. Cell proliferation was determined using an MTT assay. AGS cells were cultured in 96 -well plates $\left(10^{4}\right.$ cells/plate) with DMEM supplemented with $10 \% \mathrm{FBS}$ at $37^{\circ} \mathrm{C}$ for $24 \mathrm{~h}$. A total of $100 \mu \mathrm{l}$ DMEM containing $0.5 \mathrm{~g} / 1 \mathrm{MTT}$ was added to 
each well. Following incubation at $37^{\circ} \mathrm{C}$ for $12,24,48$ and $72 \mathrm{~h}$, the medium was removed by aspiration and $50 \mu \mathrm{l}$ dimethyl sulfoxide (DMSO) was added. Following incubation at $37^{\circ} \mathrm{C}$ for $10 \mathrm{~min}$, the absorbance of each sample at $570 \mathrm{~nm}$ was measured using a microplate reader (Tecan Infinite M200; Tecan Group Ltd., Männedorf, Switzerland).

Cell invasion assay. A Transwell assay was conducted to evaluate cell invasion using Transwell chambers pre-coated with Matrigel (BD Biosciences, Franklin Lakes, NJ, USA). A cell suspension $\left(2 \times 10^{5}\right.$ cells $\left./ \mathrm{ml}\right)$ was prepared in serum-free DMEM, and $300 \mu 1$ of the cell suspension was added into the upper chamber, while $300 \mu 1$ DMEM supplemented with $10 \%$ FBS was added into the lower chamber. Following culture at $37^{\circ} \mathrm{C}$ for $24 \mathrm{~h}$, a cotton-tipped swab was used to wipe out the cells that did not migrate through the filter. The filter was then fixed at room temperature for $20 \mathrm{~min}$ in $90 \%$ alcohol, and cells were stained with $0.1 \%$ crystal violet (Sigma-Aldrich; Merck KGaA, Darmstadt, Germany). The invaded cells were photographed under an inverted light microscope (Olympus Corporation, Tokyo, Japan). A total of $0.5 \mathrm{~g} / 1 \mathrm{MTT}$ was then added and incubated at $37^{\circ} \mathrm{C}$ for $4 \mathrm{~h}$. The medium containing MTT was subsequently removed, and $50 \mu 1$ DMSO was added to each well. Following incubation at $37^{\circ} \mathrm{C}$ for $10 \mathrm{~min}$, the optical density (OD) at $570 \mathrm{~nm}$ was measured using a microplate reader (Tecan Infinite M200; Tecan Group Ltd.). The relative cell invasive capacity was determined by the following equation: Relative cell invasive capacity $=$ OD value/OD value of the control group.

Bioinformatics prediction. TargetScan software 3.1 (www. targetscan.org) was used to predict the putative target genes of miR-30a-5p, according to the manufacturer's instructions.

Dual luciferase reporter assay. A wild-type (WT) IGF-1R 3'UTR containing the binding sequences of miR-30a-5p and a mutant type (MUT) IGF-1R 3'UTR lacking the binding sequences of miR-33b were supplied by Yearthbio (Changsha, China), and a Directed Mutagenesis kit (Stratagene; Agilent Technologies, Inc., Santa Clara, CA, USA) was used in accordance with the manufacturer's instructions. The WT or MUT IGF-1R 3'UTR were subcloned into a psiCHECK-2 vector (Promega Corporation, Madison, WI, USA) downstream of the Renilla luciferase gene. AGS cells were cultured in DMEM with $10 \% \mathrm{FBS}$ at $37^{\circ} \mathrm{C}$ in a humidified incubator containing $5 \% \mathrm{CO}_{2}$ to $60-70 \%$ confluence, then co-transfected with the luciferase reporter vectors and miR-30a-5p mimic or miR-NC using Lipofectamine 2000 (Thermo Fisher Scientific, Inc.), according to the manufacturer's instructions. Luciferase activity was measured $48 \mathrm{~h}$ after transfection using a Dual-Luciferase ${ }^{\circledR}$ Reporter Assay System (Promega Corporation) on an Lmax Microplate Luminometer (Molecular Devices, LLC, Sunnyvale, CA, UA), in accordance with the manufacturer's instructions. Using Renilla fluorescence activity as internal reference, the fluorescence values of each group were measured.

Statistical analysis. Data were presented as mean \pm standard deviation of at least three independent experiments. SPSS 17.0 software (SPSS, Inc., Chicago, IL, USA) was used to perform
Table I. Clinical characteristics of patients with gastric cancer.

\begin{tabular}{lcc}
\hline Variables & $\begin{array}{c}\text { Number of } \\
\text { patients with T1 } \\
\text { (from 13 patients) }\end{array}$ & $\begin{array}{c}\text { Number of } \\
\text { patients with T2-T4 } \\
\text { (from 30 patients) }\end{array}$ \\
\hline Age & & \\
$\leq 55$ & 4 & 11 \\
$>55$ & 9 & 19 \\
Sex & & 17 \\
Male & 8 & 13 \\
Female & 5 & \\
\hline
\end{tabular}

statistical analysis. Differences were analyzed by one-way analysis of variance and Tukey's post hoc test was performed. The relevance analysis between miR-30a-5p expression and IGF-1R expression was conducted through the Spearman's Correlation Coefficient. $\mathrm{P}<0.05$ was considered to indicate a statistically significant difference.

\section{Results}

MiR-30a-5p is downregulated in gastric cancer tissues and cell lines. To determine the role of miR-30a-5p in gastric cancer, the levels of miR-30a-5p expression were evaluated in gastric cancer tissues $(n=43)$ and normal gastric tissues $(n=10)$. RT-qPCR data indicated that the expression of miR-30a-5p was significantly decreased in gastric cancer tissues compared with normal gastric tissues $(\mathrm{P}<0.01$; Fig. $1 \mathrm{~A})$. In addition, miR-30a-5p expression was significantly lower in T2-T4 stage cancer compared with that in $\mathrm{T} 1$ stage cancer $(\mathrm{P}<0.01)$, suggesting that decreased levels of miR-30-5p were associated with advanced malignancy (Fig. 1B). The expression of miR-30a-5p in human gastric cancer cell lines was subsequently assessed. Similar to gastric cancer tissues, it was observed that miR-30a-5p was downregulated in the gastric cancer cell lines AGS, HGC27, BGC823 and SGC7901, when compared with the gastric mucosa epithelial cell line GES-1 $(\mathrm{P}<0.01$; Fig. 1C). Thus, miR-30a-5p was downregulated in gastric cancer, suggesting that reduced expression of miR-30a-5p may be involved in the malignant progression of gastric cancer.

MiR-30a-5p inhibits the proliferation and invasion of AGS cells. As AGS cells exhibited the lowest levels of miR-30a-5p among the four gastric cancer cell lines, this cell line was used in subsequent experiments. In addition, as miR-30a-5p was downregulated in gastric cancer, miR-30-5p mimic was used to upregulate its levels. Transfection with miR-30-5p mimic significantly increased the expression of miR-30-5p in AGS cells $(\mathrm{P}<0.01)$, while transfection with miR-NC had no affect on miR-30-5p expression, relative to the control group (Fig. 2A). An MTT assay was subsequently performed to evaluate cell proliferation, whereby it was observed that overexpression of miR-30a-5p significantly inhibited the proliferation of AGS cells compared with the control group $(\mathrm{P}<0.01)$, indicating that miR-30a-5p may serve a suppressive role in the proliferation of gastric cancer cells (Fig. 2B). Moreover, a Transwell assay was conduced to assess the 
A

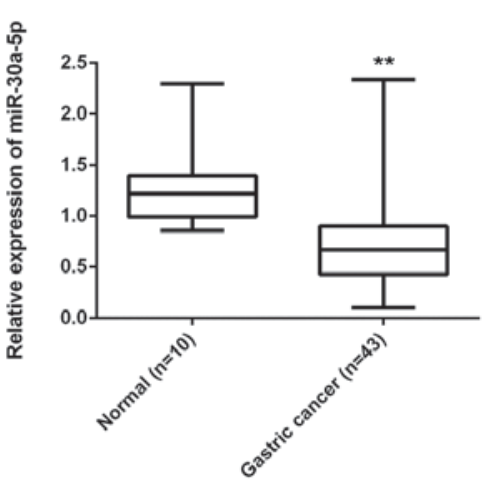

B

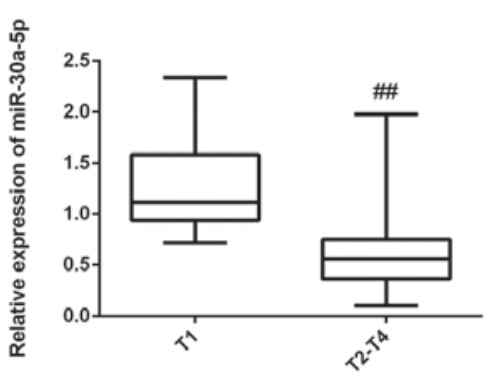

C

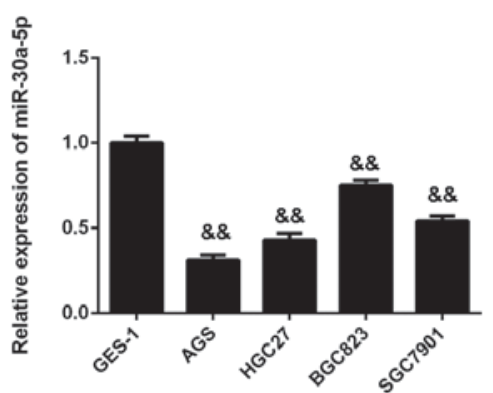

Figure 1. Expression of miR-30a-5p in gastric cancer tissues and cell lines. (A) RT-qPCR was performed to measured the expression of miR-30a-5p in gastric cancer tissues $\left(\mathrm{n}=43\right.$ ) and normal gastric tissues $(\mathrm{n}=10){ }^{* * *} \mathrm{P}<0.01$ vs. normal. (B) RT-qPCR was performed to measure the expression of miR-30a-5p in T1 stage $(\mathrm{n}=11)$ and T2-T4 stage $(\mathrm{n}=32)$ gastric cancer. ${ }^{\# \#} \mathrm{P}<0.01$ vs. T1. (C) RT-qPCR was performed to measure the relative expression of miR-30a-5p in the human gastric cancer cell lines AGS, HGC27, BGC823 and SGC7901, and the normal gastric mucosa epithelial cell line GES-1, as a control. Data are presented as mean \pm standard deviation of at least three independent experiments ${ }^{* *} \mathrm{P}<0.01$ vs. normal, ${ }^{\# *} \mathrm{P}<0.01$ vs. T1 and ${ }^{\& \&} \mathrm{P}<0.01 \mathrm{vs}$. GES -1 . miR, microRNA; RT-qPCR, reverse transcription-quantitative polymerase chain reaction.

A

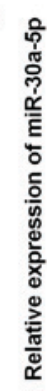

B

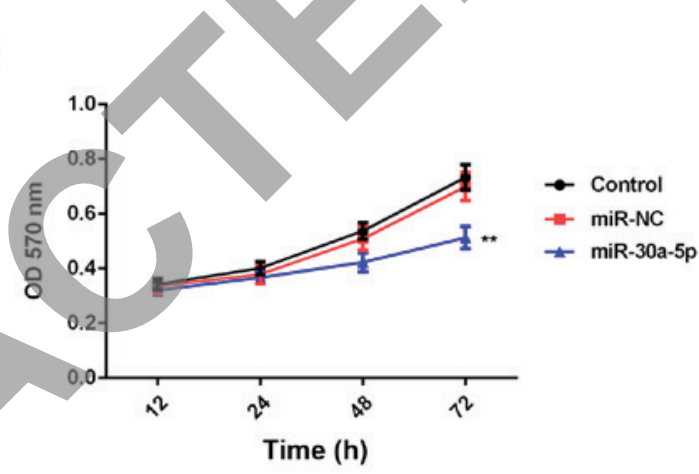

C

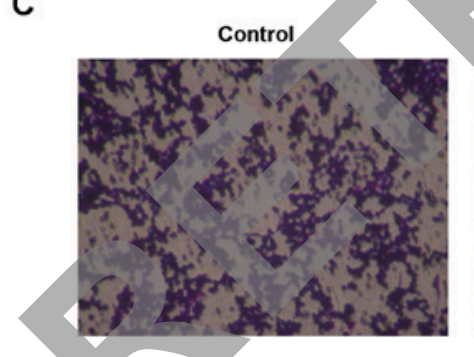

miR-NC

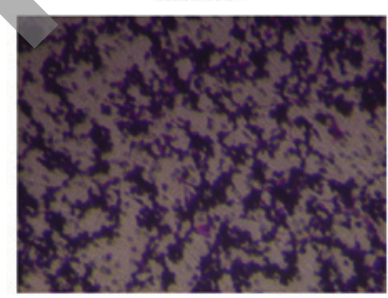

miR-30a-5p

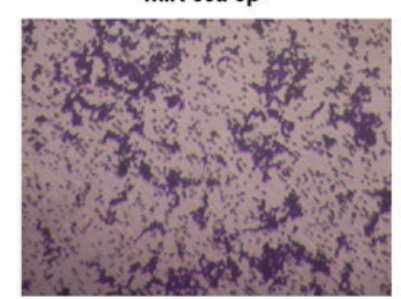

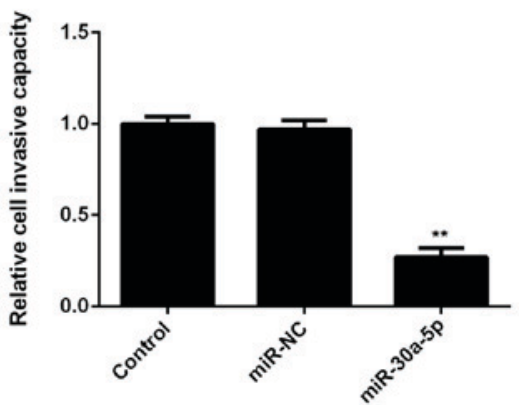

Figure 2. Effect of miR-30a-5p expression on the proliferation and invasion of gastric cancer cells. (A) Reverse transcription-quantitative polymerase chain reaction was performed to measure the relative expression of miR-30a-5p in AGS cells transfected with miR-NC and miR-30a-5p mimic. Data are presented as mean \pm standard deviation of at least three independent experiments (B) MTT and (C) Transwell assays were used to evaluate cell proliferation and invasion using crystal violet staining, respectively (magnification, $\mathrm{x} 40$ ). Data are presented as mean \pm standard deviation of at least three independent experiments, respectively. ${ }^{* *} \mathrm{P}<0.01$ vs. control. miR, microRNA; miR-NC, negative control miR; control, non-transfected AGS cells.

invasive capacities of AGS cells in each transfection group. As depicted in Fig. 2C, transfection with miR-30a-5p mimic significantly decreased the invasion of AGS cells, relative to the control group $(\mathrm{P}<0.01)$. Collectively, these data suggest that miR-30a-5p exerts inhibitory effects on the proliferation and invasion of gastric cancer cells. 
A

\begin{tabular}{|c|c|c|c|c|c|c|c|}
\hline & $\begin{array}{l}\text { Predicted consequential pairing of target region (top) } \\
\text { and miRluA (bottom) }\end{array}$ & $\begin{array}{l}\text { Site } \\
\text { type }\end{array}$ & $\begin{array}{c}\text { Context+* } \\
\text { score }\end{array}$ & $\begin{array}{c}\text { Context+r score } \\
\text { percentile }\end{array}$ & $\begin{array}{c}\text { Weighted } \\
\text { context++ score }\end{array}$ & \begin{tabular}{|c|c|}
$\begin{array}{c}\text { Conserved branch } \\
\text { length }\end{array}$ & \\
&
\end{tabular} & \\
\hline $\begin{array}{l}\text { Position } 5629.5635 \text { of IGF1R } 3 \text { UTR } \\
\text { hsa-miR-30a-5p }\end{array}$ & 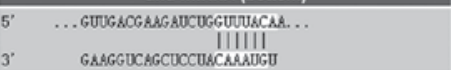 & 7 mer- & -0.07 & 54 & -0.05 & 4.901 & \\
\hline
\end{tabular}

B

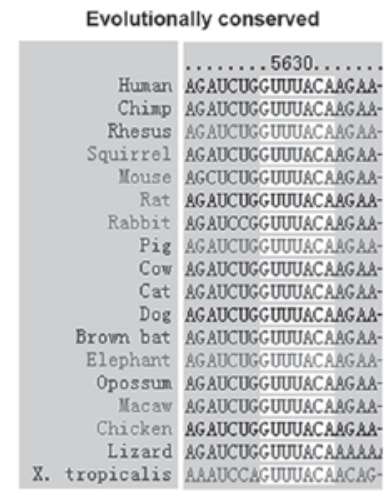

D

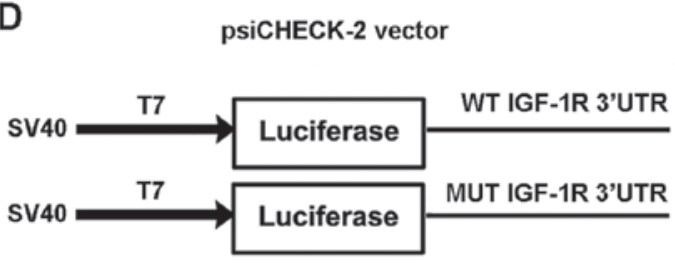

$\mathbf{F}$

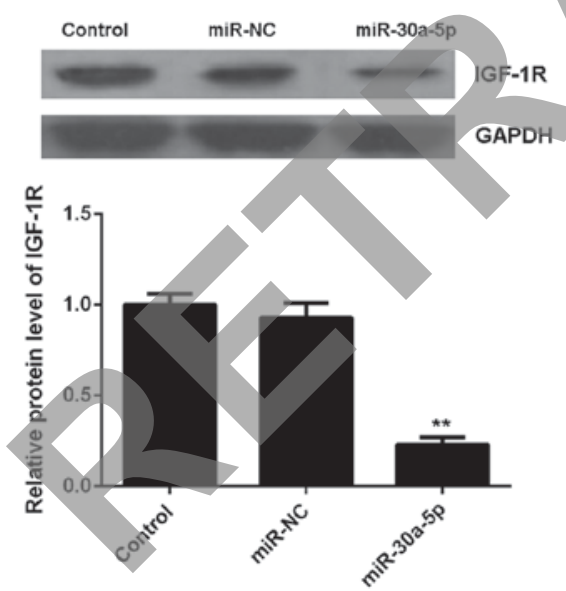

C

Seed sequences

WT IGF-1R 3'UTR 5'-...GAUCUGGUUUACAA...-3'

|| |||||

miR-30a-5p 3'-...CUCCUACAAAUGU...-5'

| $\mid$ | |

MUT IGF-1R 3'UTR 5'-...GAUCUGGAAAACAA...-3'

E

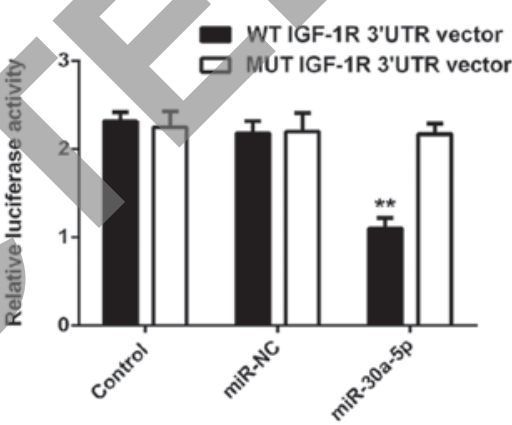

G

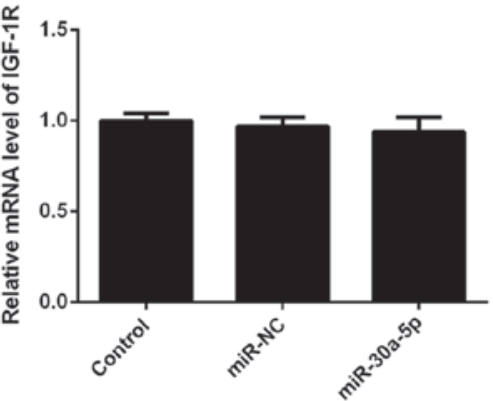

Figure 3. Targeting of IGF-1R by miR-30a-5p. (A) TargetScan software predicated that IGF-1R was a potential target of miR-30a-5p, and that (B) their targeting relationship was evolutionally conserved. (C and D) Luciferase reporter vectors containing WT and MUT IGF-1R 3'UTR were constructed. (E) Luciferase activity was significantly decreased in AGS cells co-transfected with the WT IGF-1R 3'UTR vector and miR-30a-5p mimic, but was unaffected in cells co-transfected with the MUT IGF-1R 3'UTR vector and miR-30a-5p mimic, relative to the control group. (F) Western blot analysis and (G) reverse transcription-quantitative polymerase chain reaction were used to measure the expression of IGF-1R at the protein and mRNA levels, respectively, in AGS cells transfected with miR-NC or miR-30a-5p mimic. Data are presented as mean \pm standard deviation of at least three independent experiments ${ }^{* *} \mathrm{P}<0.01$ vs. control. IGF-1R, insulin-like growth factor 1 receptor; miR, microRNA; WT, wild-type; MUT, mutant; 3'UTR, 3' untranslated region; miR-NC, negative control miR; control, non-transfected AGS cells.

$I G F-1 R$ is a target gene of miR-30a-5p. The putative targets of miR-30a-5p were investigated by bioinformatical analysis. TargetScan software predicated that IGF-1R was a potential target of miR-30a-5p (Fig. 3A), and that the targeting relationship between miR-30a-5p and IGF-1R was evolutionally conserved (Fig. 3B). To verify this prediction, reporter vectors containing WT and MUT IGF-1R 3'UTR were generated (Fig. 3C and 3D). A luciferase reporter assay was subsequently conducted, and it was observed that luciferase activity was significantly decreased in AGS cells co-transfected with the WT IGF-1R 3'UTR vector and miR-30a-5p mimic ( $\mathrm{P}<0.01$ vs. control; Fig. 3E). However, luciferase activity was unaffected in cells co-transfected with the MUT IGF-1R 3'UTR vector and miR-30a-5p mimic, relative to the control group (Fig. 3E). These data demonstrated that miR-30a-5p may directly bind to the 3'UTR of IGF-1R mRNA. As miRs negatively mediate 
A

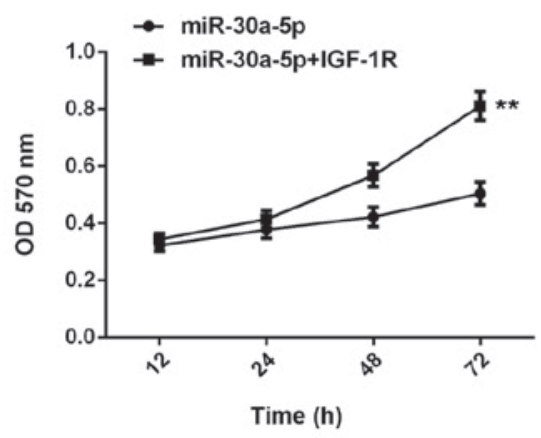

C
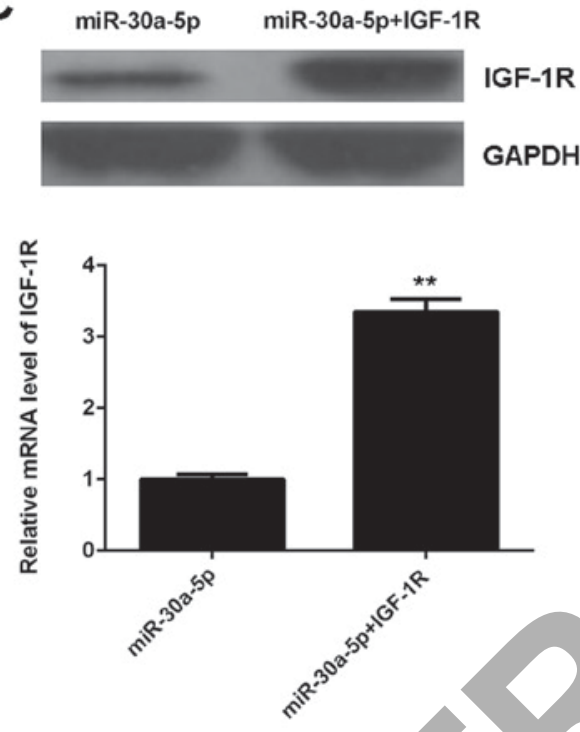

Time (h)
B

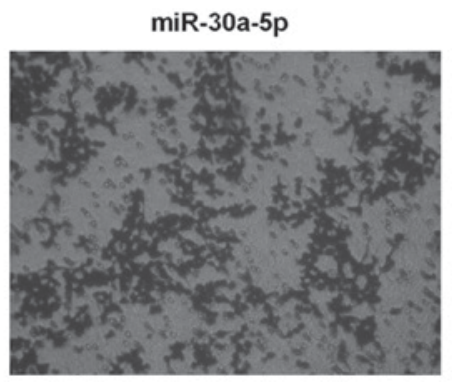

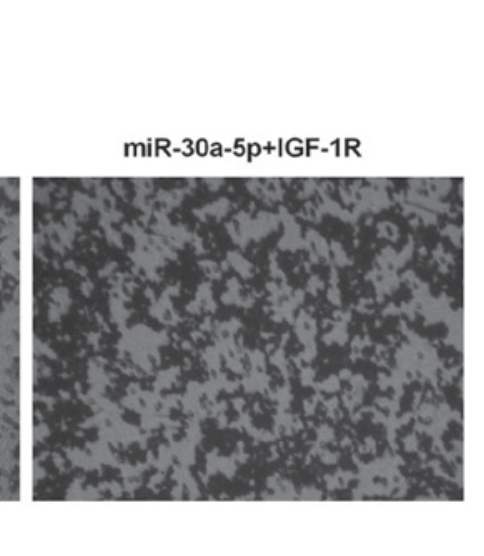
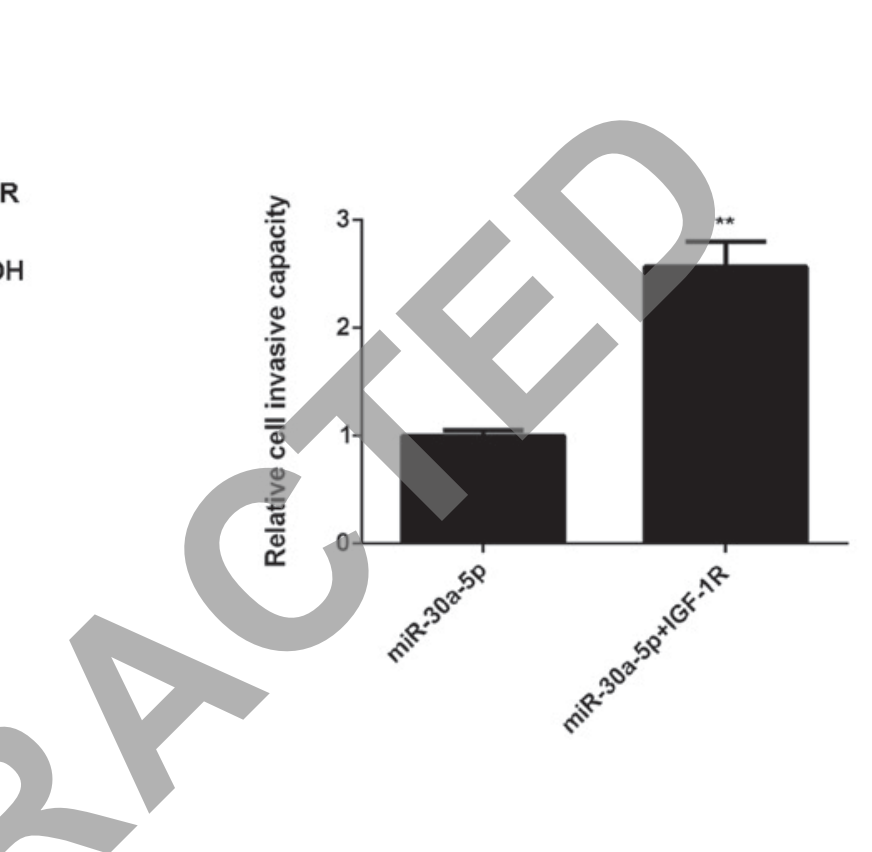

Figure 4. IGF-1R is a downstream effector of miR-30a-5p in gastric cancer. (A) MTT and (B) Transwell assays were performed to measure the proliferation and invasion using crystal violet staining (magnification, $\mathrm{x} 40$ ) of AGS cells transfected with miR-30a-5p mimic or co-transfected with miR-30a-5p mimic and IGF-1R plasmid. (C) Western blot analysis was conducted to measure the protein expression of IGF-1R. ${ }^{* *} \mathrm{P}<0.01 \mathrm{vs}$. miR-30a-5p. IGF-1R, insulin-like growth factor 1 receptor; miR, microRNA.

the expression of their target genes, the effects of miR-30a-5p on the expression of IGF-1R in AGS cells were subsequently investigated. Data from western blot analysis indicated that overexpression of miR-30-5p significantly decreased the protein expression of IGF-1R in AGS cells compared with the control group $(\mathrm{P}<0.01$; Fig. $3 \mathrm{~F})$; however, upregulation of miR-30-5p had no affect on the mRNA expression of IGF-1R in AGS cells (Fig. 3G), indicating that miR-30a-5p suppressed the expression of IGF-1R at the post-transcriptional level. Collectively, these findings indicated that miR-30a-5p negatively mediated the protein expression of IGF-1R in AGS cells by directly binding to the 3'UTR of IGF-1R mRNA.

$I G F-1 R$ acts as a downstream effector in miR-30a-5p-mediated suppression of gastric cancer proliferation and invasion. It was subsequently determined whether IGF-1R was involved in the inhibitory effects of miR-30a-5p on the proliferation and invasion of gastric cancer cells. AGS cells were transfected with miR-30a-5p mimic or co-transfected with miR-30a-5p mimic and IGF-1R plasmid. An MTT assay was then conducted to assess the effects on cell proliferation. The data indicated that cell proliferation was significantly higher in the miR-30a-5p+IGF-1R group, when compared with that in the miR-30a-5p group $(\mathrm{P}<0.01$; Fig. 4A), suggesting that miR-30a-5p inhibited the proliferation of AGS cells through direct targeting of IGF-1R. Similarly, it was observed that cell invasion was significantly upregulated in the miR-30a-5p+IGF-1R group compared to the miR-30a-5p group ( $\mathrm{P}<0.01$; Fig. 4B), suggesting that miR-30a-5p inhibited the invasion of AGS cells by directly targeting IGF-1R. To confirm these findings, levels of IGF-1R protein were measured in the miR-30a-5p and miR-30a-5p+IGF-1R groups. Results indicated that IGF-1R expression was significantly higher in the miR-30a-5p+IGF-1R group compared with the miR-30a-5p group ( $\mathrm{P}<0.01$; Fig. 4C). The above data suggested that IGF-1R was involved in the inhibitory effects of miR-30a-5p on the proliferation and invasion of gastric cancer cells.

IGF-1R is upregulated in gastric cancer tissues. RT-qPCR was performed to measure the expression of IGF-1R in gastric cancer tissues and normal gastric tissues. Results indicated that levels of IGF-1R mRNA were significantly upregulated in gastric cancer tissues compared with normal gastric tissues $(\mathrm{P}<0.01$; Fig. 5A). Furthermore, IGF-1R mRNA 
A

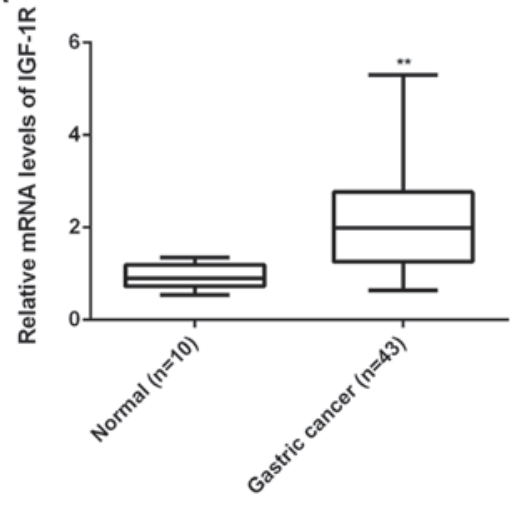

B

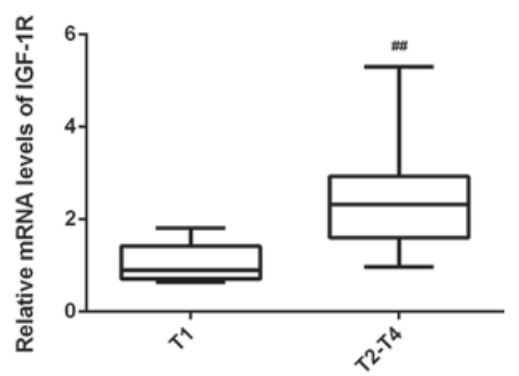

C

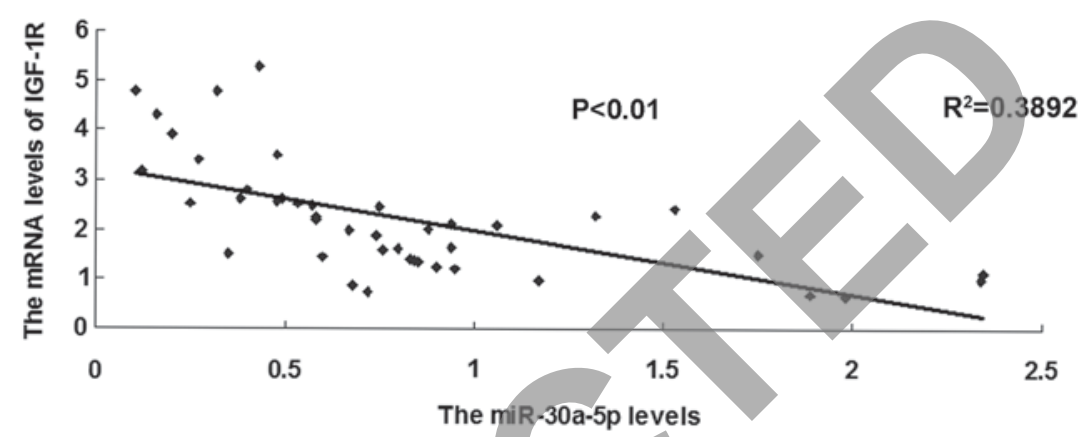

Figure 5. (A) RT-qPCR was performed to measure the expression of IGF- 1 R mRNA in gastric cancer tissues ( $\mathrm{n}=43$ ) and normal gastric tissues ( $\mathrm{n}=10$ ), (B) RT-qPCR was performed to measure the expression of IGF-1R mRNA in T1 stage ( $\mathrm{n}=11)$ and T2-T4 stage ( $\mathrm{n}=32)$ gastric cancer. Data are presented as mean \pm standard deviation of at least three independent experiments. ${ }^{*} \mathrm{P}<0.01$ vs. normal and ${ }^{\# \#} \mathrm{P}<0.01$ vs. T1. (C) An inverse correlation between the expressions of miR-30a-5p and IGF-1R mRNA in gastric cancer tissues was identified. RT-qPCR, reverse transcription-quantitative polymerase chain reaction; IGF-1R, insulin-like growth factor 1 receptor; miR, microRNA.

was significantly increased in T2-T4 stage cancer compared with $\mathrm{T} 1$ stage cancer $(\mathrm{P}<0.01$; Fig. $5 \mathrm{~B})$, suggesting that its upregulation may be involved in the malignant progression of gastric cancer. In addition, an inverse correlation between the expressions of miR-30a-5p and IGF-1R was identified in gastric cancer tissues $\left(R^{2}=0.3892, P<0.01 ;\right.$ Fig. $\left.5 C\right)$. Therefore, increased levels of IGF-1R in gastric cancer may be attributed to a downregulation in miR-30a-5p.

\section{Discussion}

A recent study identified a tumor suppressive role of miR-30a-5p in gastric cancer (14). However, the underlying molecular mechanism of miR-30a-5p in the regulation of gastric cancer proliferation and invasion is not well understood. The present study observed that miR-30a-5p was significantly downregulated in gastric cancer tissues compared with non-tumor gastric tissues. MiR-30a-5p was also downregulated in gastric cancer cell lines. Furthermore, IGF-1R was identified as a novel target of miR-30a-5p, and its levels of protein expression were negatively mediated by miR-30a-5p in AGS cells. Overexpression of miR-30a-5p significantly inhibited the proliferation and invasion of AGS cells, while restoration of IGF-1R reversed the suppressive effects of miR-30a-5p on the proliferation and invasion of AGS cells. In addition, it was observed that IGF-1R was significantly upregulated in gastric cancer tissues compared with non-tumor gastric tissues, and its expression was reversely correlated with that of miR-30a-5p in gastric cancer tissues.
MiR-30a-5p is deregulated and serves a role in many human cancers. Significant downregulation of miR-30a-5p has been identified in anaplastic thyroid carcinomas and non-small cell lung cancer $(23,24)$, while its upregulation has been documented in glioma (25) and squamous cell carcinoma of head and neck and esophagus (26), suggesting a dual role of miR-30a-5p in different cancer types. For instance, knockdown of miR-30a-5p suppressed glioma cell growth by targeting the septin-7 and PR domain zinc finger protein 1 genes, indicating that miR-30a-5p serves as an oncogene in glioma $(27,28)$. However, in colon cancer, overexpression of miR-30a-5p may inhibit the proliferation of cancer cells, while also stimulating their apoptosis and and cell cycle arrest at the G1 phase, at least in part through targeting of denticleless protein homolog, indicating that miR-30a-5p serves a suppressive role in colon cancer (29). Similarly, miR-30a-5p has been reported to inhibit cell proliferation, induce cell apoptosis and suppress the invasion and migration of hepatocellular carcinoma (HCC) cells in vitro and in vivo (30).

More recently, Li et al (31) investigated the association of a gastric cancer-specific miR signature (miR-10b, miR-21, miR-223, miR-338, let-7a, miR-30a-5p and miR-126) with the prognosis of gastric cancer patients, and observed that the miR signature was an independent predictor of overall survival and relapse-free survival, as validated in 50 patients with gastric cancer and 60 control patients. However, the exact role of miR-30a-5p in gastric cancer remains unknown. In the present study, a significant decrease in miR-30a-5p was observed in gastric cancer tissues and cell lines, suggesting that its downregulation may serve a role in the development and 
progression of gastric cancer. To the best of our knowledge, it was also demonstrated for the first time that overexpression of miR-30a-5p significantly inhibited the proliferation and invasion of AGS cells, suggesting that miR-30a-5p may also exert an inhibitory effect on the growth and metastasis of gastric cancer.

As miRs negatively regulate the protein expression of their target mRNAs, the current study investigated the putative targets of miR-30a-5p in gastric cancer. Bioinformatical analysis indicated that IGF-1R was a potential target of miR-30a-5p, and their targeting relationship was evolutionally conserved. To verify this predication, a luciferase reporter assay was performed. Results indicated that miR-30a-5p directly bound to the 3'UTR of IGF-1R mRNA, thus suggesting that IGF-1R is a direct target of miR-30a-5p. It was further observed that the expression of IGF-1R was negatively mediated by miR-503 at the post-transcriptional level in gastric cancer cells. IGF-1R functions as a key oncogene in the development and maintenance of cancer, even in the absence of its cognate ligands and intrinsic kinase activity (17). Furthermore, IGF-1R has previously been used as a therapeutic target in the treatment of cancer. For instance, Yue et al (32) generated a murine anti-IGF-1R antibody (4F2), and observed that treatment with $4 \mathrm{~F} 2$ decreased the proliferation and promoted the apoptosis of HCC cells. In the current study, upregulation of IGF-1R significantly reversed the inhibitory effects of miR-503 overexpression on the proliferation and invasion of AGS cells, indicating that IGF-1R serves as a downstream effector in miR-503-meditated suppression of gastric cancer proliferation and invasion. Moreover, IGF-1R was significantly upregulated in gastric cancer tissues compared with non-tumor gastric tissues, and its expression levels were inversely correlated with that of miR-503 in gastric cancer tissues, suggesting that high-level expression of IGF-1R in gastric cancer may be attributed to a downregulation in miR-503.

To the best of our knowledge, the present study was the first to demonstrate that miR-30a-5p, as an miR that is significantly downregulated in gastric cancer, had suppressive effects on the proliferation and invasion of gastric cancer cells by directly targeting IGF-1R. These data provide greater insight into the regulatory mechanisms of miRs in gastric cancer, and suggest that the miR-30a-5p/IGF-1R axis is a potential therapeutic target in the treatment of gastric cancer.

\section{References}

1. Siegel RL, Miller KD and Jemal A: Cancer statistics, 2015. CA Cancer J Clin 65: 5-29, 2015.

2. Torre LA, Bray F, Siegel RL, Ferlay J, Lortet-Tieulent J and Jemal A: Global cancer statistics, 2012. CA Cancer J Clin 65 : 87-108, 2015

3. Piazuelo MB and Correa P: Gastric cáncer: Overview. Colomb Med (Cali) 44: 192-201, 2013.

4. Matuszcak C, Haier J, Hummel R and Lindner K: MicroRNAs: Promising chemoresistance biomarkers in gastric cancer with diagnostic and therapeutic potential. World J Gastroenterol 20: 13658-13666, 2014.

5. Shi J, Qu YP and Hou P: Pathogenetic mechanisms in gastric cancer. World J Gastroenterol 20: 13804-13819, 2014

6. John B, Enright AJ, Aravin A, Tuschl T, Sander C and Marks DS: Human MicroRNA targets. PLoS Biol 2: e363, 2004.

7. Ambros V: The functions of animal microRNAs. Nature 431: 350-355, 2004

8. Bartel DP: MicroRNAs: Genomics, biogenesis, mechanism, and function. Cell 116: 281-297, 2004.

9. Li PF, Chen SC, Xia T, Jiang XM, Shao YF, Xiao BX and Guo JM: Non-coding RNAs and gastric cancer. World J Gastroenterol 20: $5411-5419,2014$
10. Ueda T, Volinia S, Okumura H, Shimizu M, Taccioli C, Rossi S, Alder H, Liu CG, Oue N, Yasui W, et al: Relation between microRNA expression and progression and prognosis of gastric cancer: A microRNA expression analysis. Lancet Oncol 11: 136-146, 2010.

11. Pang Y, Young CY and Yuan H: MicroRNAs and prostate cancer. Acta Biochim Biophys Sin (Shanghai) 42: 363-369, 2010.

12. Lu J, Getz G, Miska EA, Alvarez-Saavedra E, Lamb J, Peck D, Sweet-Cordero A, Ebert BL, Mak RH, Ferrando AA, et al: MicroRNA expression profiles classify human cancers. Nature 435: 834-838, 2005.

13. Feng R, Chen X, Yu Y, Su L, Yu B, Li J, Cai Q, Yan M, Liu B and Zhu Z: miR-126 functions as a tumour suppressor in human gastric cancer. Cancer Lett 298: 50-63, 2010.

14. Qiao F, Zhang K, Gong P, Wang L, Hu J, Lu S and Fan H: Decreased miR-30b-5p expression by DNMT1 methylation regulation involved in gastric cancer metastasis. Mol Biol Rep 41: 5693-5700, 2014.

15. Singh P, Alex JM and Bast F: Insulin receptor (IR) and insulin-like growth factor receptor 1 (IGF-1R) signaling systems: Novel treatment strategies for cancer. Med Oncol 31: 805, 2014.

16. King H, Aleksic T, Haluska P and Macaulay VM: Can we unlock the potential of IGF-1R inhibition in cancer therapy? Cancer Treat Rev 40: 1096-1105, 2014.

17. Crudden C, Girnita A and Girnita L: Targeting the IGF-1R: The tale of the tortoise and the hare. Front Endocrinol (Lausanne) 6: $64,2015$.

18. Chen HX and Sharon E: IGF-1R as an anti-cancer target-trials and tribulations. Chin J Cancer 32: 242-252, 2013.

19. Morishita A, Gong J and Masaki T: Targeting receptor tyrosine kinases in gastric cancer. World J Gastroenterol 20: 4536-4545, 2014.

20. Ge J, Chen Z, Huang J, Yuan W, Den Z and Chen Z: Silencing insulin-like growth factor-1 receptor expression inhibits gastric cancer cell proliferation and invasion. Mol Med Rep 11: 633-638, 2015.

21. Wittekind C: The development of the TNM classification of gastric cancer. Pathol Int 65: 399-403, 2015.

22. Livak KJ and Schmittgen TD: Analysis of relative gene expression data using real-time quantitative PCR and the 2(-Delta Delta C(T)) method. Methods 25: 402-408, 2001.

23. Visone R, Pallante P, Vecchione A, Cirombella R, Ferracin M, Ferraro A, Volinia S, Coluzzi S, Leone V, Borbone E, et al: Specific microRNAs are downregulated in human thyroid anaplastic carcinomas. Oncogene 26: 7590-7595, 2007.

24. Zhu J, Zeng Y, Xu C, Qin H, Lei Z, Shen D, Liu Z and Huang JA: Expression profile analysis of microRNAs and downregulated miR-486-5p and miR-30a-5p in non-small cell lung cancer. Oncol Rep 34: 1779-1786, 2015.

25. Wang K, Jia Z, Zou J, Zhang A, Wang G, Hao J, Wang Y, Yang S and Pu P: Analysis of hsa-miR-30a-5p expression in human gliomas. Pathol Oncol Res 19: 405-411, 2013.

26. Kimura S, Naganuma S, Susuki D, Hirono Y, Yamaguchi A, Fujieda S, Sano K and Itoh H: Expression of microRNAs in squamous cell carcinoma of human head and neck and the esophagus: miR-205 and miR-21 are specific markers for HNSCC and ESCC. Oncol Rep 23: 1625-1633, 2010.

27. Jia Z, Wang K, Wang G, Zhang A and Pu P: MiR-30a-5p antisense oligonucleotide suppresses glioma cell growth by targeting SEPT7. PLoS One 8: e55008, 2013.

28. Wang X, Wang K, Han L, Zhang A, Shi Z, Zhang K, Zhang H, Yang $\mathrm{S}, \mathrm{Pu} \mathrm{P}$, Shen $\mathrm{C}$, et al: PRDM1 is directly targeted by miR-30a-5p and modulates the $\mathrm{Wnt} / \beta$-catenin pathway in a Dkk1-dependent manner during glioma growth. Cancer Lett 331: 211-219, 2013.

29. Baraniskin A, Birkenkamp-Demtroder K, Maghnouj A, Zöllner H, Munding J, Klein-Scory S, Reinacher-Schick A, Schwarte-Waldhoff I, Schmiegel W and Hahn SA: MiR-30a-5p suppresses tumor growth in colon carcinoma by targeting DTL. Carcinogenesis 33: 732-739, 2012.

30. Dai H, Kang B, Zuo D and Zuo G: Effect of miR-30a-5p on the proliferation, apoptosis, invasion and migration of SMCC-7721 human hepatocellular carcinoma cells. Zhonghua Gan Zang Bing Za Zhi 22: 915-920, 2014 (In Chinese).

31. Li X, Zhang Y, Ding J, Wu K and Fan D: Survival prediction of gastric cancer by a seven-microRNA signature. Gut 59: 579-585, 2010.

32. Yue L, Wang Y, Wang H, Gao H, Liang J, Sui A, Xiang J, Zhou F, $\mathrm{Xu} \mathrm{C}$, Zhao W, et al: Inhibition of hepatocellular carcinoma cell growth by an anti-insulin-like growth factor-I receptor monoclonal antibody. Oncol Rep 28: 1453-1460, 2012. 